\title{
The Effects of Expertise and Physical Attractiveness upon Opinion Agreement and Liking*
}

\author{
JOANN HORAI \\ NICHOLAS NACCARI \\ ELLIOT FATOULLAH \\ Hofstra University
}

\begin{abstract}
Source characteristics of expertise (high, low, or no information) and physical attractiveness (high, low, or no photograph) were varied in a $3 \times 3$ factorial design to examine their effects on the opinion agreement of female adolescents. As expected, opinion agreement was greater for (1) the physically attractive source than for the non-differing unattractive or unpictured sources and (2) the high expert than for the nondiffering low expert or the source about whom no information was given. The nondiffering attractive and unpictured sources were liked more than the unatractive source. Implications for social influence theories are discussed.
\end{abstract}

Among the factors which have been postulated to affect the effectiveness of a source's influence attempts are expertise and interpersonal attraction (e.g., French and Raven, 1959; Tedeschi, 1972).

Expertise derives from an actor's ability to provide information to others because of his experience, education, or competence; it constitutes the denotative qualifications of a person (Tedeschi et al., 1973). Findings show that communications attributed to an expert source produce more agreement than the same communications attributed to a nonexpert (Tedeschi, 1972; Tedeschi et al., 1973).

Recent research indicates that physical attractiveness is one antecedent to interpersonal attraction (Berscheid and Walster, 1974). study.

*Thanks go to Nancy Ascher for her assistance during various phases of this 
Further, Mills and Aronson (1965) have directly demonstrated that physical attractiveness is a usable resource in social influence. A female confederate made to look attractive was more effective in influencing a male audience when she told them she wanted to persuade them than when no mention of intent was made. There were no differences between the persuasive and nonpersuasive intent conditions when the communicator was unattractive.

In addition to investigating the relationship between physical attractiveness and opinion change, Snyder and Rothbart (1971) attempted to determine whether or not the attractiveness of a source of communication had an effect on the perceived credibility of the source. They found that an attractive communicator induced more opinion change than an unattractive communicator, who was no more effective than an unpictured communicator. However, attractive and unattractive communicators were not perceived as differing in their credibility or expertise. This suggests that attractiveness and expertise may be orthogonal.

Mills and Harvey (1972), using female college students, studied the effect upon opinion change of (1) when information about the communicator was received, and (2) whether the communicator was attractive or expert. The source of communication was either an attractive nonexpert or an unattractive expert. Information concerning the communicator was presented either prior to the speech or at the end of the speech. In the before condition, differences in opinion change induced by either the attractive nonexpert or unattractive expert were not significant. In the after condition, however, subjects showed significantly less agreement with the unattractive expert than with the attractive nonexpert. The authors suggested that the processes which produce agreement with an attractive communicator are not identical with those which produce agreement with an expert communicator. A major weakness in the Mills and Harvey (1972) study is that expertise and attractiveness were not completely manipulated. The attractive source was nonexpert, while the expert source was unattractive. Therefore, it is difficult to ascertain whether or not these variables affected one another when they were combined and how this combination affected opinion change.

It was hypothesized in the present study that (1) the physically attractive source would produce more opinion agreement than the unattractive source and (2) the expert source would elicit more opinion agreement than the nonexpert source. The interaction was not expected to be significant. 


\section{Method}

Subjects and design. Subjects were 80 white ninth-grade females in a Long Island public junior high school located in a middle income community. Three levels of physical attractiveness (high, low, and no photograph) and three levels of expertise (high, low, and no information) constituted the $3 \times 3$ factorial design. Eight $S$ s were randomly assigned to each of the 9 cells of the design. An additional 8 -subject control group was given the opinion question without having been exposed to the communication.

Procedure. After being greeted and seated, $S$ s were informed by $E$ that they were participating in a study which was interested in young people's reactions to opinions expressed in newspapers. $S$ s were told that the article which they would be reading appeared in the "Letters to the Editor" section of a leading local newspaper. The main theme of the communication centered on the value of receiving a broad, general education in high school. Specific recommendations included taking courses in psychology, sociology, marriage and child rearing, law, and marketing, in addition to regular sequences of English, science, mathematics, and the social sciences. An attempt was made to compose the communication so that it would not be forceful enough to influence opinion agreement independent of source characteristics.

Earlier, students drawn from the same population as the experimental $S$ s rated (on a 7-point scale) nine occupations and ten photographs of males taken from a college yearbook. The highestand lowest-rated photographs and occupations were used in the present study. On the cover of the booklet was (1) a photograph of an attractive or unattractive male or no photograph and (2) information that the communicator was either a professor of education presently teaching at a university (high expertise) or a teacher's aide presently working at a high school (low expertise) or no information. $S$ s were asked to read the article carefully and to answer the questions which followed regarding their agreement with the main theme of the article, impressions of the communicator, liking for the communicator, and recall of the content of the communication, respectively. $S$ s responded to these questions in terms of 7-choice Likert-type scales. The opinion question asked Ss to indicate their agreement with the statement that "students should take a wide range of subjects in school." A manipulation check included two items rating the communicator's (1) attractiveness and (2) his intelligence (the perceived expertise of the communicator). Subjects then rated their affective response to the author, and 
finally, were asked five questions testing their recall of the content of the communication.

An $87 S$ control group was told that they were participating in a study which was interested in getting the opinion of young people concerning an issue which has been written about recently in newspapers. They received only the opinion question.

Following completion of the questionnaire, $S \mathrm{~s}$ were debriefed, thanked, and dismissed.

\section{Results and Discussion}

Three $\times 3$ analyses of variance were performed on the five dependent measures. Duncan multiple comparison tests were used where appropriate.

A significant main effect of physical attractiveness on $S s^{\prime}$ perception of the author's attractiveness was found $(\mathrm{F}=16.300, \mathrm{df}=$ $2 / 63, \mathrm{p}<.001) . S \mathrm{~s}$ in the high physical attractiveness condition $(\overline{\mathrm{X}}=$ $5.13)$ rated the communicator more attractive $(p<.01)$ than $S \mathrm{~s}$ in the no photograph condition $(\overline{\mathrm{X}}=4.27)$ or the low physical attractiveness $(\overline{\mathrm{X}}=3.29)$ condition. The unpictured author received a higher rating than the author depicted to be low in physical attractiveness $(p<.01)$. A comparison of the means of the significant main effect of expertise on intelligence $(\mathrm{F}=7.784, \mathrm{df}=$ $2 / 63, \mathrm{p}<.01)$ indicated that $S \mathrm{~s}$ perceived the university professor $(\overline{\mathrm{X}}$ $=5.58)$ to be more intelligent $(\mathrm{p}<.01)$ than either the teacher's aide $(\overline{\mathrm{X}}=4.92)$ or the author about whom no information was given $(\overline{\mathrm{X}}=$ 4.63). The latter two groups did not differ significantly. No other effects approached significance on these two dependent measures. The manipulations did generate the desired perceptions of attractiveness, and perceived expertise. Further, physical attractiveness and expertise contributed independently to the impression of the communicator. The source's physical attractiveness did not affect $S s$ ' perception of the author's expertise, as Snyder and Rothbart (1971) found, nor did the source's expertise affect $S$ s' perception of his attractiveness.

It should be noted that analysis of the memory items revealed no significant effects of the independent variables on $S$ s' recall of factual material. The overall mean recall was 4.71 correct out of a maximum of five correct. Hence, obtained results were not due to differences in recall as a function of source characteristics. This replicates the findings of several studies manipulating expertise (e.g., Hovland and Weiss, 1951) and extends it to physical attractiveness as an influence base. 
Main effects of physical attractiveness $(\mathrm{F}=5.889, \mathrm{df}=2 / 63, \mathrm{p}<$ $.01)$ and expertise $(\mathrm{F}=4.470, \mathrm{df}=2 / 63, \mathrm{p},<.05)$ were found on $\mathrm{Ss}$ ' agreement with the main theme of the communication. Ss who read the communication attributed to the physically attractive author $(\overline{\mathrm{X}}$ $=6.21$ ) felt that students should take a wide range of subjects in high school $(\mathrm{p}<.05)$ more than did $S$ s who read either the unattractive $(\bar{X}=5.25)$ or unpictured $(\bar{X}=4.84)$ communicator's article. The latter two groups did not significantly differ. Replicating previous findings on the effects of expertise on opinion agreement, the university professor $(\bar{X}=6.13)$ elicited more opinion agreement $(p$ $<.05)$ than either the teacher's aide $(\overline{\mathrm{X}}=4.96)$ or the author about whom no information was given $(\overline{\mathrm{X}}=5.20)$. No significant difference was found between the latter two groups. The interaction term was not significant. Hence, as expected, physical attractiveness and expertise do make independent contributions in inducing opinion agreement. By factorializing physical attractiveness and expertise in the before condition of the Mills and Harvey (1972) study, the present experiment demonstrated that when information concerning these two source characteristics is received prior to a communication, they do authenticate or deauthenticate an actor's communication, as suggested by Tedeschi et al. (1973).

Mills and Harvey (1972) attempted to describe the attractive nonexpert source and the unattractive expert communicator so that they would be about equally persuasive in the before condition. The difference between the means in their two before conditions did not reach significance. Similarly, Duncan tests in the present study revealed that the low expertise-attractive cell did not differ significantly from the high expertise-unattractive cell. This could be expected since the effects of the variables on opinion agreement were orthogonal. Future research needs to factorialize physical attractiveness and expertise in the after condition of the Mills and Harvey study. This would determine whether post-communication information about the author contributes to the decrease in agreement in that condition, and if so, which information about the author (expert, unattractive, or both) contributes most. If, as Mills and Harvey (1972) suggest, the processes mediating agreement with an attractive communicator differ from those which produce agreement with an expert source, such an experiment would further identify the nature of these processes.

As mentioned earlier, so that the effects of source characteristics could be more clearly limned, an attempt was made to compose a communication which by itself would not be forceful enough to 
elicit opinion agreement. That this attempt was successful is indicated by a nonsignificant difference (using Dunnett's critical difference test) between the no information-no photograph cell of the factorial design and the $8-S$ control group in which $S$ s indicated their opinion without reading the article.

The only factor to influence $S$ s' liking for the author was physical attractiveness $(F=3.753, \mathrm{df}=2 / 63, \mathrm{p}<.05)$. The physically unattractive source $(\overline{\mathrm{X}}=4.04)$ was liked less than either the physically attractive $(\overline{\mathrm{X}}=5.22, \mathrm{p}<.01)$ or the unpictured $(\overline{\mathrm{X}}=$ $4.71, \mathrm{p}<.05)$ source. The latter two groups did not differ significantly. A source whose physical attributes become known before communication with a target tends to produce more liking and opinion agreement if that source is physically attractive rather than unattractive. Liking, however, may not be the sufficient condition for opinion agreement.

\section{REFERENCES}

Berschied, E. and E. Walster

1974 "Physical attractiveness." Pp. 157-215 in L. Berkowitz (ed.), Advances in Experimental Social Psychology, Vol. 7. New York: Academic Press.

French, J. R. P., Jr. and B. Raven

1959 "The bases of social power." Pp. 150-157 in D. Cartwright (ed.), Studies in Social Power. Ann Arbor: Institute of Social Research.

Hovland, C. and W. Weiss

1951 "The influence of source credibility on communication effectiveness." Public Opinion Quarterly 15:635-650.

Mills, J. and E. Aronson

1965 "Opinion change as a function of the communicator's attractivensss and desire to influence." Journal of Personality and Social Psychology $1: 173-177$.

Mills, J. and J. Harvey

1972 "Opinion change as a function of when information about the communicator is received and whether he is attractive or expert." Journal of Personality and Social Psychology 21: 52-55.

Snyder, M. and M. Rothbart

1971 "Communicator attractiveness and opinion change." Canadian Journal of Behavioral Science 3:377-387.

Tedeschi, J. T. (ed.)

1972 The Social Influence Processes. Chicago: Aldine-Atherton.

Tedeschi, J. T., B. Schlenker and T. Bonoma

1973 Conflict, Power, and Games. Chicago: Aldine. 
Copyright of Sociometry is the property of American Sociological Association. The copyright in an individual article may be maintained by the author in certain cases. Content may not be copied or emailed to multiple sites or posted to a listserv without the copyright holder's express written permission. However, users may print, download, or email articles for individual use. 